\title{
CRIAÇÃO DE UM PERIÓDICO CIENTÍFICO ONLINE EM UMA INSTITUIÇÃO DE ENSINO SUPERIOR PÚBLICA
}

\section{CREACIÓN DE UN PERIÓDICO CIENTÍFICO ONLINE EN UNA INSTITUCIÓN PÚBLICA DE EDUCACIÓN SUPERIOR}

\author{
Sandra Gomes de Oliveira Reis* \\ Evandro de Melo Catelão**
}

\begin{abstract}
RESUMO:
Introdução: Este trabalho fornece uma visão geral da implantação de um periódico científico em uma instituição de ensino pública, com o objetivo de atribuir maior facilidade de acesso à produção científica dos pesquisadores no país e no mundo. Objetivo: A pesquisa teve como objetivo fornecer um relato sobre a implantação na instituição estudada. Metodologia: Para essa investigação, buscou-se contextualizar historicamente o periódico científico impresso e o eletrônico, destacando as semelhanças de suas características editoriais e os benefícios que o periódico eletrônico tem propiciado à comunidade científica. Resultados: $O$ estudo enfatiza o papel das tecnologias da informação e comunicação e sua grande contribuição para o mercado editorial que vem sendo provido de várias alternativas eletrônicas que facilitam a produção dos periódicos científicos tanto impressos como eletrônicos. Conclusões: Diante da realidade atual, com avanços tecnológicos tão rápidos, o periódico eletrônico provoca grande impacto uma vez que a comunidade obtém informação nova a cada instante e em todas as áreas do conhecimento, se configurando como um recurso eficaz para a disseminação da informação e para a produtividade científica, técnica e cultural no âmbito da instituição estudada.
\end{abstract}

Palavras-chave: Periódico científico. Periódico eletrônico. Comunicação científica.

\footnotetext{
*Mestranda Ciência da Informação da Universidade Estadual de Londrina -UEL. Email: sandrareismga@gmail.com.

**Doutor em Letras pela Universidade Federal do Paraná - UFPR. Docente Universidade Tecnológica Federal do Paraná - Campus Londrina. E-mail: evandrocatelao@gmail.com.
} 


\section{INTRODUÇÃO}

A produção e a disseminação do conhecimento científico são atividades realizadas principalmente no universo das instituições de ensino superior (IESs), sendo esta uma de suas principais missões, demonstrando a sua importância para a construção da sociedade. Esse dado também é apresentado por Kuramoto (2006), para ele a informação científica é a base para o desenvolvimento científico e tecnológico de um país. Estando, nesse tipo de informação, os resultados das pesquisas científicas que são divulgados à comunidade por meio de artigos em revistas.

Para a atividade científica de uma instituição ser consolidada é necessário seu registro em algum suporte. Nesse aspecto, destacam-se os periódicos como uma forma usada para essa divulgação. Por outro lado, nem sempre as pessoas têm conhecimento da estrutura de um periódico e do trajeto desde seu início até sua publicação, significando dizer que, mesmo sendo ele o veículo por excelência da produção científica, requerem-se esforços de diferentes naturezas até sua chegada aos usuários.

Segundo Barradas (2005, p. 13), já se passaram três séculos desde a criação dos periódicos científicos. De dois pioneiros, um surgiu na França e o outro na Inglaterra, ambos em 1665, já com a função de divulgar os resultados de pesquisas. Pelas mesmas características composicionais de um periódico impresso, surgiu o periódico eletrônico, tornando mais acessível em termos de produção e divulgação científica.

Nesse cenário, esta pesquisa buscou mostrar as etapas para a implantação de um periódico científico no Campus Londrina da Universidade Tecnológica Federal do Paraná (UTFPR-LD), a instituição conta com um Comitê Gestor que avalia o periódico que será criado e dá o aceite sobre sua publicação ou não. Nesses limites, o presente trabalho busca mostrar o caminho percorrido até esse aceite.

\section{BREVE RELATO HISTÓRICO}

O Portal de Periódicos Científicos Institucionais da UTFPR (PERI<https://periodicos.utfpr.edu.br/>) é uma das ferramentas que constituem

Inf. Inf., Londrina, v. 22, n. 2, p. 546 - 563, maio/ago., 2017. http:www.uel.br/revistas/informacao/ 
o Portal de Informação em Acesso Aberto da UTFPR (PIAA), desenvolvido para promover de forma facilitada o acesso à produção da Universidade, e sua atuação compete:

a) Todos os periódicos científicos editados pela Instituição deverão ser gerenciados com o auxílio da plataforma do Sistema Eletrônico de Editoração de Revistas (SEER) e disponibilizados no PERI;

b) Os periódicos científicos institucionais deverão ter capacidade de integração com sistemas nacionais e internacionais, observando-se o uso de padrões e protocolos de integração, em especial aqueles definidos no modelo Open Archives, que por meio do Open Archives Iniciative Protocol for Metadata Harvesting (OAI-PMH) terá mecanismos de exposição de metadados do arquivo para facilitar sua coleta por terceiros;

c) Os editores de periódicos solicitarão aos autores de artigos apenas os direitos de primeira publicação, possibilitando seu depósito em outros repositórios digitais;

d) Os periódicos seriam gerenciados de acordo com a Política Editorial de Periódicos vigente na Instituição;

e) Cada periódico será administrado por um Editor, apoiado por um Conselho Editorial heterogêneo, constituído de integrantes que devem ser especialistas reconhecidos, de origem nacional e internacional, devidamente identificados na publicação. Além disso, deverá existir, ainda, um Conselho Consultivo renomado, constituído de especialistas nas áreas de cobertura do periódico, atentando-se à cobertura nacional e internacional, evitando assim a endogenia. Esses parâmetros deverão ser seguidos para a criação de novos periódicos e também para os periódicos já existentes na instituição.

O campus Londrina, ainda não tinha nenhum periódico científico institucional, em função disso, e também seguindo a filosofia de acesso aberto a toda informação produzida em IES, o Programa de Mestrado Profissional em Ensino de Ciências Humanas, Sociais e da Natureza se viu diante do desafio de criar esse periódico. O primeiro passo foi apresentar essa ideia ao diretor do campus, em seguida marcamos a primeira reunião com o intuito de estruturar a ideia. Nesse ínterim, foi criado o Comitê Gestor de Avaliação de Periódicos Científicos da UTFPR, e com sua criação, todos os novos periódicos para ter a 
chancela da instituição devem ser elaborados dentro dos critérios da Política Editorial de Periódicos Científicos da UTFPR que integram os seguintes critérios:

- $\quad$ Proposta de Título do Periódico;

- Indicação do título abreviado do periódico;

- Vinculação a um Câmpus e a um Departamento/Curso ou Programa de Pós-Graduação, se houver;

- Justificativa para a criação da publicação;

- $\quad$ Foco e escopo da publicação;

- $\quad$ Proposta de periodicidade e perspectiva da quantidade de artigos publicados por número;

- Idiomas;

- $\quad$ Captação de produção;

- $\quad$ Proposta de Diretrizes para Autores;

- $\quad$ Política de direito autoral adotada;

- Editor;

- Composição do Conselho Editorial;

- Composição do Comitê Científico.

Após o preenchimento dessa proposta, o Comitê Gestor analisa e monta seu parecer assinalando se é favorável ou não para sua criação. Sendo favorável, o Comitê cria um espaço, utilizando o SEER no PERI, um e-mail institucional para a Revista e dá todo suporte para os editores não só nesse processo, como na implantação.

\section{O PERIÓDICO CIENTÍFICO}

O termo periódico, de acordo com o AACR2, é compreendido como a publicação que, utilizando qualquer tipo de suporte, é editado com o caráter de continuidade, sem previsão de término (CRUZ et al., 2003). Isso nos remete ao significado de que é toda publicação que se edita em intervalos regulares, que podem ser semanais, quinzenais, mensais, trimestrais, anuais etc. Para a divulgação científica, essa continuidade é uma forma de não só fazer uma 
pesquisa ser reconhecida, como também ajudar no fomento de novas pesquisas.

Foi dentro desse terreno fértil que surgiu o que se entende hoje por periódico científico. O primeiro foi um periódico francês, que era semanal e divulgava catálogos de livros, necrológios de pessoas famosas e sua biografia, notícias sobre novas descobertas nas ciências e nas artes, informações sobre física e química, sentenças dos tribunais seculares e eclesiásticos, numa tentativa de abarcar todas as ciências (BARRADAS, 2005, p.13).

O primeiro periódico foi o Journaldes Sçavants, cujo número inicial foi editado em 5 de janeiro de 1665, por Denis de Sallo, que obteve o privilégio de imprimi-lo em 8 de agosto de 1664. Esse periódico não só divulgava os catálogos de livros, mas descrevia o conteúdo e a utilidade desses livros; divulgava a censura de universidades e informava aos leitores sobre acontecimentos de curiosidade humana (LEMOS, 1968).

O segundo periódico surgiu em março de 1665, ano seguinte ao da primeira publicação do periódico francês, com o título de Philosophical Transactions, da Royal Societyof London, da Inglaterra (BARRADAS, 2005, p.13). Com esse novo meio de comunicação científica, os cientistas puderam aposentar as trocas de informações que antes eram feitas por cartas entre seus pares.

Já no Brasil, os primeiros periódicos que surgiram foram a Gazeta Médica do Rio de Janeiro em 1862 e Gazeta Médica da Bahia em 1866 (BARRAVIERA, 1997, p.51). Nesse sentido, observamos que os periódicos brasileiros foram criados quase duzentos anos após o precursor francês (principalmente por uma questão histórica/cultural), contudo, com o passar dos anos, eles foram se aprimorando e atualmente vêm superando as expectativas, buscando qualidade e respeito no meio científico, tanto no formato impresso como no eletrônico.

Em sentido próximo ao periódico impresso, a ideia de um periódico eletrônico não é algo tão novo, pois já em 1977, para espanto de alguns, Frederik Lancaster previa que a comunidade científica criaria, transmitiria e receberia informações através de terminais; os cientistas teriam instrumentos para uma comunicação sem fronteiras geográficas, com a divulgação de 
artigos por meios eletrônicos (SIMEÃO, 2001). Isso se constituiu em uma previsão acertada das revoluções que o periódico experimentaria.

Para Mueller (2006), o periódico científico eletrônico surgiu efetivamente e ganhou formas inovadoras a partir da década de 90 , despertando nos pesquisadores a esperança de uma mudança radical no sistema tradicional de comunicação científica. De forma complementar, Lemos (2005) afirma também que a década de 90 aparece como o início das publicações científicas online, mas afirmar qual foi o primeiro periódico eletrônico não é uma tarefa tão fácil assim, considerando-se que o termo periódico eletrônico nos remete a uma publicação distribuída em disquete, cd-rom ou pela web. Não obstante, podemos sugerir que o primeiro, pelo menos a utilizar avaliação por pares, é o Post modern Culture, surgido em setembro de 1990, primeiro em formato de correio eletrônico, depois em disquete; e em janeiro de 1994 aparece a versão em hipermídia na internet.

Podemos afirmar que, mesmo sem uma data e um título que realmente indique um precursor (característica das novas mídias digitais), os periódicos científicos eletrônicos realmente vieram para ficar, e a cada dia têm surgido novos títulos, na sua maioria só em formato eletrônico. Claro que há ainda periódicos científicos nos dois formatos - o impresso e o eletrônico - mas o eletrônico vem realmente tomando um espaço grande na disseminação do conhecimento. Tal fato pode estar relacionado ao crescimento do número de computadores conectados a redes nas universidades, como também o computador pessoal ter tomado destaque nas residências (COSTA; SILVA; COSTA, 2001).

No âmbito da disseminação científica de uma forma geral, os periódicos científicos estão se transformando em suportes de extrema importância para o meio acadêmico. Sua evolução, principalmente com relação ao seu formato, é inegável, sendo o meio eletrônico, por excelência, o mais utilizado na atualidade para os periódicos científicos, que, originalmente, eram impressos. Há que considerar ainda aqueles que iniciaram sua publicação em formato eletrônico e não têm equivalente no formato impresso, além de formas de divulgação como os arquivos de fonte aberta (open source). Esses dispositivos aumentam significativamente as oportunidades de acesso aos interessados 
que, dessa forma, sentem a necessidade de buscar na literatura o seu surgimento e sua estruturação, para, a partir desses dados, montar um projeto para um periódico científico eletrônico.

Para Meadows (1999), a comunicação formal é mais eficiente no processo de comunicação científica. Afirma que a escrita tem uma absorção mais rápida que a oralidade, por esse aspecto o periódico vem se destacando como um canal formal de muita utilização, pois, além do suporte utilizado, a sua publicação se dá em intervalos de tempos e, com isso, as pesquisas são mais rapidamente absorvidas no meio científico.

O periódico é um canal formal de comunicação científica e nasceu com a clara necessidade de divulgar as pesquisas e estudos de membros de uma área. A comunicação científica tem um papel essencial nos meios científicos e, há algum tempo, ela é utilizada para divulgar os resultados de pesquisas e fomentar a sua discussão. Nesse contexto, surge a necessidade de criar um suporte para esse fim, pois as comunicações dessas pesquisas eram feitas entre seus pares, como mostra Lemos (1968, p.3):

No curso da elaboração de suas pesquisas, voltava-se para colegas de outras localidades e, por meio de correspondência pessoal, esclareciam questões e trocavam ideias. Esta forma de comunicação epistolar supria a falta de meios adequados para a veiculação de ideias e experimentos científicos. Sempre houve a necessidade de troca entre os pesquisadores, não só para divulgar a pesquisa feita, mas também para fomentar novas discussões e preservar o que fora descoberto.

Desde a Segunda Guerra Mundial, as tecnologias de informação e comunicação (TICs) transformaram as relações tanto políticas e sociais quanto econômicas, sendo que nesse âmbito a tecnologia que mais se destacou foi a Internet. Essa última passou a influenciar de forma direta o comportamento da sociedade, por proporcionar acesso fácil e rápido a documentos e/ou informações que geograficamente estariam distantes ou com alguma barreira linguística, em alguns casos sob veto político e/ou religioso (BORBA; COSTA; MARTINS, 2006, p.2).

Com o aumento da procura por informações, surgiu a necessidade de publicação e disseminação das informações geradas. Por sua vez, o 
crescimento e aperfeiçoamento das novas tecnologias da informação e comunicação permitiram que a comunicação científica se ampliasse ainda mais, através dos canais formais, como as publicações eletrônicas (CRESPO; CAREGNATO, 2004).

Desde o surgimento dos periódicos eletrônicos, podemos distinguir os suportes ou formatos em dois tipos: o formato impresso e o eletrônico. No formato impresso não há subdivisões, só esse formato, mas o eletrônico pode ser subdividido. A tecnologia nos dá várias opções, e com isso há um pouco de confusão na hora de caracterizar essas divisões, podendo-se até encontrar em algumas publicações o termo digital.

A estrutura de um periódico científico, com o passar dos anos, foi se aprimorando e estabelecendo uma estrutura única, de modo que, quando se ouve o termo periódico científico ou revista científica, pode-se visualizar uma capa, seguida de expediente, sumário, editorial, artigos e, no final, as normas para publicação.

A estrutura de um periódico científico impresso é baseada nas normas da Associação Brasileira de Normas Técnicas - ABNT. No caso de periódicos, a norma utilizada como referência é a NBR 6021 - Publicação Periódica Científica Impressa, na qual são especificados os requisitos para apresentação dos elementos da estrutura de organização física de uma publicação periódica científica impressa (ABNT, 2003, grifo nosso).

O periódico científico eletrônico utiliza os mesmos critérios estabelecidos para o impresso, e na maioria das vezes a estrutura remete à versão impressa, que deverá haver: número do ISSN; título; capa (Layout); expediente; sumário; resumos e artigos (PDFs).

Com o crescimento da produção de periódicos científicos eletrônicos, percebemos ser importante que as publicações mantenham a qualidade e demais características que contribuam para os altos níveis de uso e utilidade (KING; TENOPIR, 1998). Por isso, a maioria dos periódicos segue a mesma estrutura utilizada no impresso, o qual já usa as normas da ABNT, para efeito de padronização.

A parte fundamental em um periódico científico eletrônico, mais do que sua estrutura, é a qualidade da sua editoração e a de seus artigos. Ao criar 
uma revista podemos pesquisar critérios utilizados por indexadores que indicam as características intrínsecas e extrínsecas para avaliação de um periódico, que são:

Qualidade de conteúdo (percentual de artigos originais e qualidade dos artigos para a sua área);

- Apresentação gráfica (distribuição física de seus elementos imagens/título);

- $\quad$ Normalização (seguir com rigor as normas adotadas pela revista) (KRZYZANOWSKI; FERREIRA; MEDEIROS, 2005, p.58-59).

Para Barbalho (2005), além dos citados acima, devem ser observadas ainda:

- Qualidade do corpo editorial e a integridade do processo de avaliação;

- Padronização aceita internacionalmente (aqui entra a manutenção da periodicidade);

- Utilização de recursos gráficos atuais;

- Um relacionamento eficiente entre editores e leitores.

Com o uso do suporte eletrônico, surgiu com maior frequência a publicação de todo o tipo de material bibliográfico, pois a facilidade em transmitir, enviar, receber e alterar o formato inicial do documento apresenta-se como o fator que promoveu a expansão das TICs no meio acadêmico (BORBA; COSTA; MARTINS, 2006, p.5).

A utilização dos periódicos científicos eletrônicos tem trazido para a comunidade científica maior agilidade na disseminação dos resultados de suas pesquisas e na recuperação dessas informações. Para Damásio (2006), não é só essa a vantagem, mas também o acesso de qualquer ponto do mundo, o acesso ao conteúdo integral ou parcial e o acesso de vários anos de publicação. A acessibilidade e a atualização constante dos periódicos eletrônicos têm mostrado que a adoção dessa forma de disponibilização tem sido um ganho não só às instituições, como também aos autores.

O software Open Journal Systems - OJS, projeto da University British Columbia e da Simon Fraser University Library, foi criado com o objetivo 
específico de atender à demanda de construção e administração de uma revista eletrônica; e dentro do Movimento de Acesso Livre à Informação Científica, da filosofia de Open Access, há uma busca por disseminar a informação científica sem barreiras (MÁRDERO ARELLANO, 2005).

Partindo dessa premissa, o IBICT, em julho de 2003, criou um grupo de trabalho para traduzir e estudar o OJS, visando implantá-lo na revista Ciência da Informação do instituto. Em dezembro, quando foi apresentada a versão em português, a comunidade externa solicitou o seu uso. Esse sistema facilita o processo editorial e possibilita aos autores o acompanhamento da avaliação de seu trabalho junto à revista. Ante essa inovação e dentro da filosofia de acesso livre da informação, o software SEER - Sistema Eletrônico de Editoração de Revistas, criado para editoração eletrônica de revistas, começou a ser distribuído entre as pessoas que o solicitavam (MÁRDERO ARELLANO; SANTOS; FONSECA, 2005).

O objetivo central do SEER é prestar assistência aos editores em todas as etapas do processo de editoração, desde a submissão, avaliação por consultores até publicação online e indexação do periódico científico; e como é um software livre, o sistema de gerenciamento pode ser definido de acordo com as políticas de publicação do periódico que o estiver utilizando (MÁRDERO ARELLANO; FERREIRA; CAREGNATO, 2005).

As vantagens de sua utilização são inúmeras, tanto na divulgação como no gerenciamento dos periódicos eletrônicos. Para Márdero Arellano, Ferreira e Caregnato (2005, p.220), isso ocorre por ele permitir uma completa autonomia na tomada de decisões sobre o fluxo editorial, a publicação e o acesso por parte do editor. É este quem define as etapas do processo editorial, seguindo a política definida pela revista, mas dispondo de assistência e registro online em todas as fases do gerenciamento. No que se refere ao autor, possibilita espaço para comunicação com o editor e também permite o acompanhamento da avaliação e editoração do seu trabalho.

O software também opera com um sistema amigável, facilitando o uso entre as pessoas que não tenham um conhecimento mais aprofundado de informática e, dessa forma, atingindo um número maior de usuários. Outra vantagem é a redução do custo, já que a tramitação é feita por e-mail e assim 
diminui o gasto com papel e correio. Ao se publicar a revista, é possível enviála automaticamente aos autores, o que faz diminuir o tempo de espera pelo impresso, já que, após a diagramação de uma revista, ainda é preciso fazer orçamento para impressão para, assim, enviar o material para as gráficas.

\subsection{O Papel do Periódico Científico na Divulgação do Conhecimento}

A geração e a disseminação do conhecimento têm sido realizadas principalmente no âmbito das Instituições de Ensino Superior (IESs), por meio de um dos principais pilares da missão universitária, a pesquisa científica e tecnológica. A universidade é um espaço que, para Rodrigues, Lima e Garcia (1998, p.153), pode ser definido como de promoção do cultivo da pluralidade do pensamento e, por consequência, das formas de abordagem e interpretação da realidade. É papel da universidade, também, permitir a análise dos mais diferentes objetos de estudo. À universidade seria permitido, portanto, colocar tudo em questionamento.

Neste sentido, são inquestionáveis as contribuições das pesquisas científicas e tecnológicas para o desenvolvimento econômico e social de um país, pois é por meio delas que um país alcança conhecimentos que levam à melhoria das condições de vida de sua população. Daí a importância da divulgação do conhecimento científico, pois uma pesquisa só é reconhecida como tal após a análise dos seus pares. É nesse aspecto que a comunicação se faz tão pertinente.

Para Meadows (1999, p.161), "a realização de pesquisas e a comunicação de seus resultados são atividades inseparáveis". Não há como o pesquisador utilizar anos e anos fazendo uma pesquisa para não divulgá-la ou simplesmente arquivá-la. A importância da produção do conhecimento para a construção das sociedades contemporâneas - determinando inclusive a riqueza e o poder das nações - não é mais discutível; o que se discute agora é a forma como esse produto será disseminado.

O conhecimento científico pode ser transmitido por canais formais, que são aqueles com informações já estabelecidas ou comprovadas através de estudos; nesse quesito entram livros, periódicos etc. Canais informais são os contatos entre os interlocutores, como visitas, contatos interpessoais, reuniões 
e trocas de correspondência; e os semiformais se constituem no uso simultâneo dos dois canais (ARAÚJO, 2002 apud SCHULTZE, 2005).

$\mathrm{Na}$ maioria das vezes, os canais formais são utilizados, no meio científico, pelos periódicos, pois o autor, ao repassar à comunidade seus conhecimentos científicos, afirma-se como cientista - reconhecimento pelos pares e pela própria instituição, que para a manutenção de periódicos exige uma produção intensa de publicações originais - (SCHULTZE, 2005). Talvez seja por essas forças ou correlacionadas que a comunicação científica vive uma fase de contradições e paradoxos.

As mudanças no processo de comunicação científica, do mais formal ao informal no meio acadêmico, e transformações introduzidas pelas novas tecnologias da informação e pelo periódico científico eletrônico constituem um dos maiores destaques da atualidade acadêmica (COSTA; SILVA; COSTA, 2001). Nesses limites, o periódico (de uma forma geral) vem se destacando como um canal formal de muita utilização e um dos mais adequados meios de disseminação da informação científica. É nessa vertente que tentamos iniciar um periódico eletrônico que esteja em compasso com a qualidade, buscando textos que contribuam com a comunicação científica do país.

Entende-se que disponibilizar uma forma de acesso ao conhecimento produzido na universidade é um ponto de crucial importância para o desenvolvimento científico, como também para a formação profissional de qualidade; por isso a democratização do conhecimento científico é imprescindível tanto para a formação dos futuros profissionais quanto para o crescimento da sociedade em geral.

\section{DISCUSSÃO DOS DADOS}

Após a primeira reunião com a equipe de trabalho, definiu-se o título do periódico e foi escolhido o editor chefe para a formatação da proposta para criação do periódico. $O$ editor chefe foi escolhido dentre os professores que integram o programa de mestrado e com a colaboração de uma bibliotecária designada para esse processo, lotada no departamento de pós-graduação do campus.

Inf. Inf., Londrina, v. 22, n. 2, p. 546 - 563, maio/ago., 2017. 
O projeto foi estruturado em:

Título do periódico: Ensino e Tecnologia em Revista, nome esse escolhido, após uma vasta pesquisa para descartar homônimos.

Justificativa e o foco e escopo da publicação, para a criação da publicação: contribuir para a ampliação e consolidação do campo de estudos em ensino e aprendizagem das áreas de Humanas, Exatas, Sociais e da Natureza com pesquisas que estudam o processo de ensino-aprendizagem e seus produtos, assim auxiliando na produção de conhecimentos e de novas estratégias pedagógicas para melhorar a interação entre docente e discente nessas áreas.

Proposta de periodicidade e perspectiva da quantidade de artigos publicados por número: Semestral, com publicações em fluxo contínuo, podendo ocorrer a publicação de números temáticos especiais. 16 artigos por ano, com no mínimo 8 artigos em cada número.

Idiomas: português, inglês ou espanhol.

Captação de produção: entre seus pares e divulgação via e-mail

Proposta de diretrizes para autores: template com as normas baseadas na ABNT.

Política de direito autoral adotada: autores mantêm os direitos autorais e concedem à revista o direito de primeira publicação, com o trabalho simultaneamente licenciado sob a Creative Commons Attribution-Non Commercial License que permite o compartilhamento do trabalho com reconhecimento da autoria do trabalho e publicação inicial nesta revista.

O periódico incentiva o depósito do artigo, mencionando a fonte original de publicação, em repositórios institucionais ou digitais, em consonância com o Movimento de Acesso Aberto à Informação Científica, com vistas a ampliar a visibilidade.

\section{Editor, composição do Conselho Editorial e do Comitê Científico:} professores do programa de mestrado e de instituições de outros estados.

O projeto foi submetido em novembro de 2015 e após duas reformulação foi aprovado em julho de 2016, essas reformulações se deram justamente para adequar o futuro periódico aos critérios do PERI, sempre com objetivo de criar um periódico não só de qualidade como com vistas a atender aos critérios de 
indexadores nacionais e internacionais. A publicação do primeiro número se deu no início de setembro de 2017.

\section{CONSIDERAÇÕES PARCIAIS}

A busca da comunidade científica (por ter acesso e obter informações para o desenvolvimento de suas pesquisas) é um reflexo do processo de mudança que se dá de forma acelerada e fomenta o crescimento de tecnologias que visam facilitar esse acesso. A internet, o correio eletrônico, as bases de dados, os periódicos eletrônicos e também os livros eletrônicos, já estão, ao menos parcialmente, incorporados ao dia-a-dia dos pesquisadores e acadêmicos (OLIVEIRA, 2006). Podemos destacar o periódico científico eletrônico ao disponibilizar os seus volumes em meio eletrônico, com a absorção dessas novas tecnologias.

Nesse cenário (aceitação do novo veículo de disseminação da informação) com mais vantagens do que desvantagens desse novo formato de publicação para os periódicos da IES, a criação do periódico se fortalece.

No mês de julho do ano de 2016, foi autorizada a criação do periódico e como a captação de artigos para os dois primeiros números, já estavam ocorrendo durante o processo de validação da proposta e também divulgação com o objetivo de angariar autores, avaliadores e leitores. O primeiro número foi publicado no início de setembro de 2017, com oito artigos e todos com registro de DOI. Sendo seu endereço de acesso o seguinte: $<$ https://periodicos.utfpr.edu.br/etr/issue/view/333>.

Essa busca, por facilitar o acesso à informação produzida pelo país, visa a colaborar com o crescimento da ciência, em que o partilhar de informações fortalece e fomenta novas pesquisas. Tendo em vista o estudo dos dados, podemos observar que um periódico eletrônico (pela visualização de outros estudos e até mesmo pelos dados históricos descritos anteriormente) constituise sempre como uma contribuição vantajosa à instituição promotora e aos pesquisadores envolvidos, não só por facilitar acesso à informação para a comunidade acadêmica e científica interna e externa, mas também por ser uma forma de divulgar publicações com o compartilhamento de pesquisas de forma rápida e confiável. $\mathrm{O}$ futuro para o periódico assegura a conquista de mais

Inf. Inf., Londrina, v. 22, n. 2, p. 546 - 563, maio/ago., 2017. http:www.uel.br/revistas/informacao/ 
entradas de artigos para tramitação e a consolidação do seu nome entre as várias outras publicações da mesma esfera.

\section{REFERÊNCIAS}

ASSOCIAÇÃO BRASILEIRA DE NORMAS TÉCNICAS. NBR-6021/1994: Informação e Documentação - Publicação periódica científica impressa Apresentação. Rio de Janeiro: ABNT, 2003.

BARBALHO, C. R. S. Periódico Científico: Parâmetros para avaliação de qualidade. In: FERREIRA, Sueli Mara Soares Pinto; TARGINO, M. G. (Org.). Preparação de revistas Científicas: teoria e pratica. São Paulo: Reichmann \& Autores, 2005. p. 123-158.

BARRADAS, M. M. Prefácio. In: FERREIRA, S. M. S. P.; TARGINO, M. G. (Org.). Preparação de revistas Científicas: teoria e pratica. São Paulo: Reichmann \& Autores, 2005. p.

BARRAVIERA, B. Editoração Eletrônica Científica. Botucatu, SP: FUNDIBIO, 1997.

BORBA, M. S. A.; COSTA, G. C. N.; MARTINS, R. A. C. O Periódico

Científico On-Line. 2006. Disponível

em:<http://www.snbu2006. ufba.br/soac/viewpaper.php?id=227>. Acesso em: 05 jan. 2016.

COSTA, S. M. S.; SILVA, W. A. A.; COSTA, M. B. Publicações científicas eletrônicas no Brasil: mudanças na comunicação formal, também? Revista de Biblioteconomia de Brasília, Brasília, v. 25, n. 1, p. 57-76, jan./jun. 2001. Disponível em:<http://repositorio.unb.br/handle/10482/631>. Acesso em: 05 jan. 2016.

CRESPO, I. M.; CAREGNATO, S. E. Periódicos científicos eletrônicos: identificação de características e estudos de três casos na área de comunicação. 2004. Disponível em:<http://www.portcom.intercom.org.br/institucional/a rede/endocom/2004/Cr espo.PDF>. Acesso em: 05 jan. 2016.

CRUZ, A.A.A. C. et al. Impacto dos periódicos eletrônicos em bibliotecas universitárias. Ciência da Informação, Brasília, v. 32, n. 2, p. 47-53, 2003. Disponível em:<http://www.scielo.br/pdf/ci/v32n2/17032.pdf>. Acesso em: 05 jan. 2016. 
KING, D. W.; TENOPIR, C. A publicação de revistas eletrônicas: economia da produção, distribuição e uso. Ciência da Informação, Brasília, v. 27, n. 2, 1998. Disponível em:

$<$ http://www.scielo.br/scielo.php?script=sci arttext\&pid=S010019651998000200010\&lng=pt\&nrm=isso>. Acesso em: 05 jan. 2016.

KRZYZANOWSKI, R. F.; FERREIRA, M. C. G.; MEDEIROS, R. Instrumental aos Autores para preparação de trabalhos científicos. In: FERREIRA, S. M. S. P.; TARGINO, M. G. (org). Preparação de revistas Científicas: teoria e pratica. São Paulo: Reichmann \& Autores, 2005. p. 55-72.

KURAMOTO, H. Informação científica: proposta de um novo modelo para o Brasil. Ciência da Informação, Brasília, v. 35, n. 2, p.91-102, maio/ago. 2006. Disponível em: <http://www.scielo.br/scielo.php?pid=S0100$19652006000200010 \&$ script=sci abstract\&tlng=pt>. Acesso em: 05 jan. 2016.

LEMOS, A. A. B. Presente e futuro do periódico científico. Correio Braziliense, Brasília, 13 jul. 1968, p. 3. Disponível em:<http://www4.unirio.br/museologia/textos/presente e futuro periodico.pdf>. Acesso em: 05 jan. 2016.

. Publicar e perecer. Ciência da Informação, Brasília, v. 34, n. 2, p. 7-8, maio/ago. 2005. Disponível em: $<$ http://www.scielo.br/scielo.php?script=sci arttext\&pid=S0100$19652005000200001>$. Acesso em: 05 jan. 2016.

MÁRDERO ARELLANO, M. A.; SANTOS, R.; FONSECA, R. SEER: Disseminação de um sistema eletrônico para editoração de revistas científicas no Brasil. Arquivística.net, Rio de Janeiro, v. 1, n. 2, p. 75-82, jul./dez. 2005. Disponível em: <https://core.ac.uk/download/pdf/11889732.pdf>. Acesso em: 05 jan. 2016.

OJS/SEER: uma ferramenta de software livre para periódicos científicos. In: MIRANDA, A.; SIMEÃO, E. Informação e Tecnologia: Conceitos e Recortes. Brasília, DF: UNB, 2005. v. 1. p. 220-227.

; FERREIRA, S. M. S. P.; CAREGNATO, S. E. Editoração eletrônica de revistas científicas com suporte do Protocolo OAI. In: FERREIRA, S. M. S. P.; TARGINO, M. G. (Org.). Preparação de revistas Científicas: teoria e pratica. São Paulo: Reichmann \& Autores, 2005. p. 195-229.

MEADOWS, A. J. A comunicação Científica. Brasília, DF: Briquet de Lemos Livros, 1999.

MUELLER, S. P. M. A comunicação científica e o movimento de acesso livre ao conhecimento. Ciência da Informação, Brasília, v. 35, n. 2, p. 27-38, maio/ago. 2006. Disponível em: <http://revista.ibict.br/ciinf/article/view/1138/1293>. Acesso em: 05 jan. 2016.

Inf. Inf., Londrina, v. 22, n. 2, p. 546 - 563, maio/ago., 2017. http:www.uel.br/revistas/informacao/ 
OLIVEIRA, E. B. P. M. Uso de Periódico Científico Eletrônico por Docentes e Pós-graduados do Instituto de Geociências da USP. 2006. 139 f.

Dissertação (Mestrado em Ciência da Informação) - Escola de Comunicação e Artes, Universidade de São Paulo, São Paulo. Disponível em:<http://www.teses.usp.br/teses/disponiveis/27/27151/tde-18122006102446/>. Acesso em: 05 jan. 2016.

RODRIGUES, M. E. F.; LIMA, M. H. T. F.; GARCIA, M. J. O. A normalização no contexto da comunicação científica. Perspectiva em Ciência da Informação, Belo Horizonte, v. 3, n. 2, p. 147-156, jul./dez. 1998. Disponível em: $<$ http://www.brapci.ufpr.br/brapci/ repositorio/2010/11/pdf 33a3cde8ee 00126 58.pdf>. Acesso em: 09 nov. 2006.

SCHULTZ, S. Características de periódicos científicos produzidos por editoras universitárias brasileiras. Informação e Sociedade, v. 15, n. 2, p. 157-179, 2005. Disponível em:

<http://www.ies.ufpb.br/ojs2/index.php/ies/article/view/36/1517>. Acesso em: 05 jan. 2016.

SIMEÃO, E. L. M. S. Experiência da Revista de Biblioteconomia de Brasília na Internet. Revista de Biblioteconomia de Brasília, Brasília, v. 25, n. 1, jan./jun. 2001. Disponível em: <http://repositorio.unb.br/handle/10482/908>. Acesso em: 05 jan. 2016.

Title

Creation of a scientific journal on line in an institution of higher education publishes

\begin{abstract}
:
Introduction: This paper provides an overview of the implementation of a scientific journal in a public educational institution, in order to give easier access to scientific production of researchers in the country and the world. Objective: The research aimed to provide a report on the implementation in the studied institution. Methodology: For this research, contextualize historically sought to the printed journal and electronic, highlighting the similarities of their editorial features and benefits that electronic journal has provided the scientific community. Results: The study emphasizes the role of information and communication technologies and their great contribution to the publishing market which has been provided with a number of electronic alternatives that facilitate the production of scientific journals both printed and electronic. Conclusions: Proves, therefore, given the current reality, with technological advances so fast, the electronic journal causes great impact because the community will have access to new information at every moment and in all areas of knowledge, shaping up as an effective remedy for the dissemination of information and scientific productivity, technical and cultural under the studied institution.
\end{abstract}

Keywords: Scientific periodical. Eletronic periodical. Scientific communication.

Inf. Inf., Londrina, v. 22, n. 2, p. 546 - 563, maio/ago., 2017. http:www.uel.br/revistas/informacao/ 


\section{Título}

Creación de un periódico científico on line en una institución de enseñanza superior pública

\section{Resumen:}

Introducción: Este trabajo proporciona una visión general de la implantación de un periódico científico en una institución de enseñanza pública, con el objetivo de asignar mayor facilidad de acceso a la producción científica de los investigadores en el país y en el mundo. Objetivo: La investigación tuvo como objetivo proporcionar un relato sobre la implantación en la institución estudiada. Metodología: Para esa investigación, se buscó contextualizar históricamente el periódico científico impreso y el electrónico, destacando las semejanzas de sus características editoriales y los beneficios que el periódico electrónico ha propiciado a la comunidad científica. Resultados: El estudio enfatiza el papel de las tecnologías de la información y comunicación y su gran contribución al mercado editorial que viene siendo provisto de varias alternativas electrónicas que facilitan la producción de los periódicos científicos tanto impresos y electrónicos. Conclusiones: Por lo tanto, ante la realidad actual, con avances tecnológicos tan rápidos, el periódico electrónico provoca gran impacto una vez que la comunidad obtiene información nueva a cada instante y en todas las áreas del conocimiento, configurándose como un recurso eficaz para la diseminación de la comunicación información y para la productividad científica, técnica y cultural en el ámbito de la institución estudiada.

Palabras clave: Periódico científico. Periódico electrónico. Comunicación científica.

Recebido: 30.08 .2017

Aceito: 30.09 .2017

Inf. Inf., Londrina, v. 22, n. 2, p. 546 - 563, maio/ago., 2017. 